\title{
A Statistical Damage Constitutive Model for Geomaterials under Plane-Strain Biaxial Stress State
}

\author{
Hongwei Zhang, ${ }^{1,2}$ Zhijun Wan, ${ }^{1}$ Chaoyi Wang, ${ }^{2}$ Zhaoyang Ma, \\ Yuan Zhang, ${ }^{1}$ and Jingyi Cheng ${ }^{1}$ \\ ${ }^{1}$ Key Laboratory of Deep Coal Resource Mining (CUMT), Ministry of Education of China, School of Mines, \\ China University of Mining \& Technology, Xuzhou 221116, China \\ ${ }^{2}$ Department of Energy and Mineral Engineering, EMS Energy Institute and G3 Center, The Pennsylvania State University, \\ University Park, PA 16802, USA \\ Correspondence should be addressed to Zhijun Wan; zhjwan@126.com
}

Received 30 May 2017; Accepted 10 September 2017; Published 17 October 2017

Academic Editor: John D. Clayton

Copyright ( 2017 Hongwei Zhang et al. This is an open access article distributed under the Creative Commons Attribution License, which permits unrestricted use, distribution, and reproduction in any medium, provided the original work is properly cited.

\begin{abstract}
The mechanical behavior of geomaterials under plane-strain biaxial stress state (PSBSS, a special case of biaxial stress state) is often considered in geotechnical structures such as highwall and longwall coal pillars. In this study, a modified statistical damage constitutive model based on Weibull distribution was established to explain the mechanical behavior of rocks under the PSBSS. The modified Wiebols-Cook criterion, Drucker-Prager criterion, and extremum method were adopted in this model to estimate the peak strength of rock, the strength level of microscopic element, and the statistical parameters of model, respectively. Besides, laboratory tests for brittle and ductile geomaterials under PSBSS were conducted using the modified surface instability detection apparatus to validate the accuracy of the proposed statistical damage model. Finally, the relationships between mechanical parameters and statistical parameters were studied and discussed.
\end{abstract}

\section{Introduction}

The deformation of rocks is a significant mechanical property in rock engineering [1], such as tunnel excavation, underground coal mining, and hydraulic fracturing. Numerous studies have been conducted to explore the relationship between the loading force and the deformation of geomaterials (also known as constitutive relationship) after the establishment of the first constitutive equation (i.e., Hook's law) [2-13]. Statistical damage constitutive model, based on the Weibull distribution, plasticity theory, and rock failure criteria [14-16], has been developed afterwards to further investigate the deformation process and failure mechanism of rocks under uniaxial and triaxial stress states [17-23]. However, statistical damage model for rocks under planestrain biaxial stress state (PSBSS) is rarely available.

The PSBSS [24], different from uniaxial and triaxial stress states, is a special case of the biaxial stress state. Geomaterials under the PSBSS are often encountered in geotechnical structures, such as pillar between adjacent tunnels and highwall and longwall mining coal pillar (Figures 1(a), 1(b), and 1(c)). In these engineering structures, one dimension (i.e., the direction of $\sigma_{2}$ in Figure 1) is relatively larger than the others (i.e., the directions of $\sigma_{1}$ and $\sigma_{3}$ ), and the principal strain in the direction of the longest dimension is constrained and generally assumed to be zero (i.e., $\varepsilon_{2}=0$ ) (Figure $1(d)$ ).

Identically, plane-strain biaxial compression tests on brittle and ductile geomaterials are also limited, although studies have been done to explore the stress-strain behavior and constitutive model of geomaterials under biaxial stress state since 1969 [2, 25-29]. Papamichos et al. [30] designed a plane-strain biaxial apparatus to investigate the surface spalling phenomena in rocks, indicating a shear-mode failure for brittle rocks under the PSBSS. Tao [31] tested the failure strength of soft and hard coal specimens under the PSBSS and they found out that greater failure strengths will appear under the PSBSS than those under uniaxial stress state for both kinds of coal specimens. In addition, the postpeak behavior of geomaterials (Figure 2) is an important factor to the safety of underground structures and should be considered when 


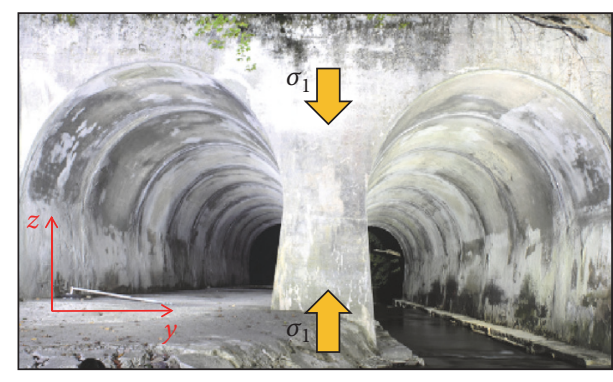

(a)

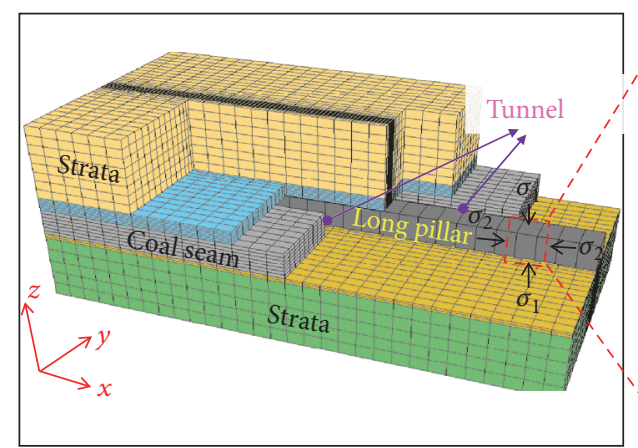

(c)

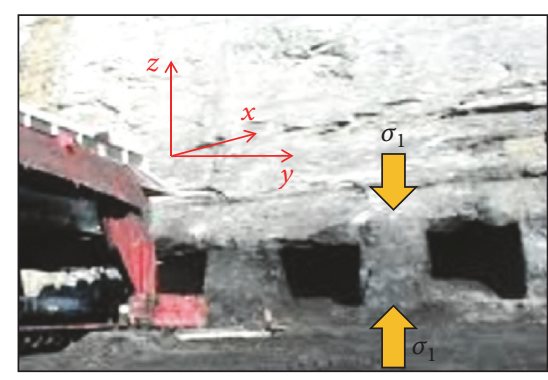

(b)

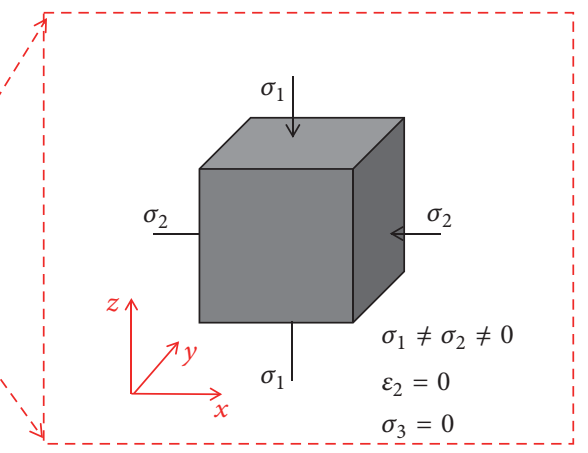

(d)

FIGURE 1: Typical pillars under plane-strain biaxial stress state (PSBSS). (a) Rock pillar between adjacent tunnels; (b) coal pillar in highwall mining system; (c) coal pillar in longwall mining system; (d) a block under plane-strain biaxial compression stress state.

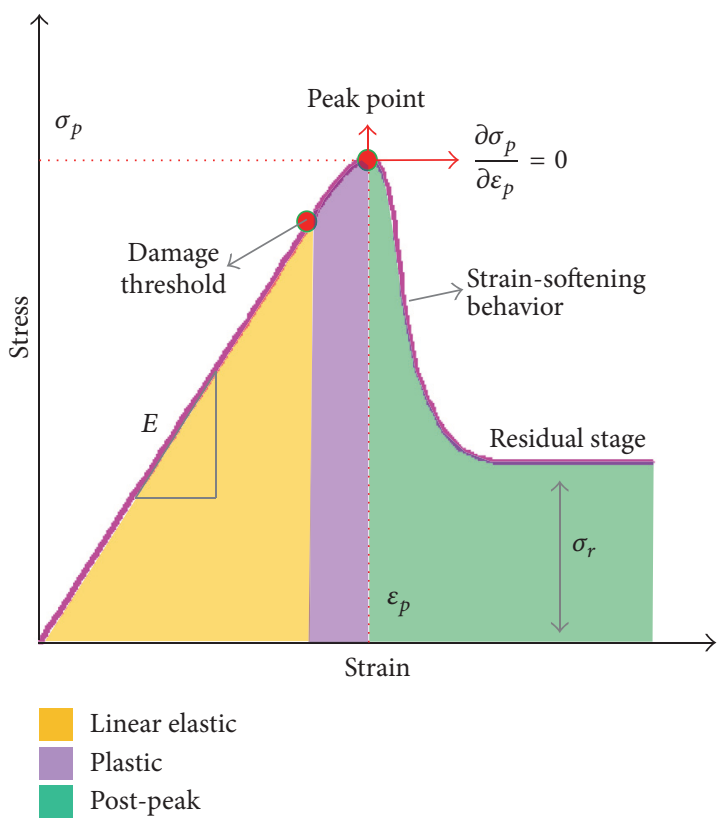

FIgURE 2: Typical stress-strain relationship. $\sigma_{p}$ is the peak/failure strength of materials, $\varepsilon_{p}$ the peak strain, and $\sigma_{r}$ the residual strength.

dealing with the geotechnical engineering [1]. The shortcoming of the above studies is that the stress-strain behaviors are not taken into consideration. Furthermore, it is difficult to establish physical models elaborating the postfailure behavior for rocks because of the plastic deformation. Thus, a modified statistical damage constitutive model should be established to illustrate the stress-strain behaviors, especially, the postpeak behavior of rocks under the PSBSS.

Accumulation and coalescence of stress-induced microcracks have been suggested as the fracture and damage mechanisms of rocks. Microcrack density was thought to be the governing factor for the elastic and fracture mechanical properties [33-37]. As shown in Figure 2, the stress-strain curve implies that the rock is first considered to be linear elastic with a constant modulus $(E)$ before the damage threshold is reached, and then the rock is thought to be damaged. The damage degree can be represented by the reduction of the elastic modulus [38-40]. Residual stage occurs at the end of the postpeak stage in the stress-strain curve (Figure 2). This stage, representing the residual loading capability of rocks, is vital to the stability of structures. In order to take the residual strength $\left(\sigma_{r}\right)$ into consideration when establishing the constitutive damage model, some researchers [41, 42] introduced a self-determined coefficient. However, it is a challenge to determine these coefficients. Instead of introducing the predetermined coefficient, Zhao et al. [32] employed the Mohr-Coulomb criterion in the light of the classical damage model [17] to estimate the residual strength of rocks.

In this article, a modified constitutive damage model is presented to elaborate the stress-strain behavior of rocks under the PSBSS. We first introduce the constitutive equation for rocks under the PSBSS. Afterwards, a statistical damage constitutive model is established by analyzing the damage variable and residual strength of microscopic elements. Thirdly, we employ the modified Wiebols-Cook criterion, Drucker-Prager criterion, and extremum method to estimate 
the peak strength of rocks, strength level of microscopic elements, and statistical parameters, respectively. We then introduce the experimental methodology and, finally, validate and discuss the results.

\section{Model}

2.1. Elastic-Constitutive Model for Rocks under the PSBSS. According to the plane-strain concept, the principal strain in the direction of the longest dimension is constrained and can be assumed as zero (i.e., $\varepsilon_{2}=0$ ) (Figures $1(\mathrm{c})$ and $1(\mathrm{~d})$ ) [43]. In addition, there is no stress perpendicular to the free surface after the excavation (i.e., $\sigma_{3}=0$ ). Thus, the stressstrain relationship for isotropic elasticity material is

$$
\sigma_{1}=\frac{E \varepsilon_{1}}{\left(1-\mu^{2}\right)},
$$

where $\sigma_{1}, E$, and $\mu$ are the maximum principle stress, elastic modulus, maximum principle strain, and Poisson's ratio, respectively. The intermediate principle stress $\sigma_{2}$ is closely related to maximum principle stress $\sigma_{2}$ and $\sigma_{2}=\mu \sigma_{1}$.

To obtain the stress-strain curve, three stages should be settled. The linear elastic stage of rocks under the PSBSS can be determined by (1). After the elastic stage, the stress-strain behavior can be calculated by the degradation of modulus and solution of the damage variable. The last stage (i.e., residual stage) can be determined by considering the residual strength of the damaged rock.

\subsection{Statistical Damage Constitutive Model \\ for Rocks under the PSBSS}

2.2.1. Evolution of the Damage Variable (D). In the new statistical damage constitutive model, rocks are assumed to consist of numerous mesoscopic elements. According to the statistical damage theory, any mesoscopic element has dual states (i.e., intact and damaged) and strengths of the mesoscopic elements follow a Weibull distribution [14, 18, 44]:

$$
P(F)=\frac{m}{F_{0}}\left(\frac{F}{F_{0}}\right)^{m-1} \exp \left[-\left(\frac{F}{F_{0}}\right)^{m}\right],
$$

where $F$ is the strength level and $F_{0}$ the scale parameter; statistical parameter $(m)$ represents the shape of the function and determines the concentration of strength level $(F)$.

After the damage threshold point (Figure 2), Weibull distribution is employed to estimate the damage distribution of mesoscopic elements. The density of damaged elements can be determined by the damage variable $(D)[17,32]$. As shown in Figure 3, with strength level $F$ increasing from 0 to $F^{\prime}$, the damage variable $(D)$ can be expressed as

$$
D=\int_{0}^{F^{\prime}} P(F) d F=1-\exp \left[-\left(\frac{F^{\prime}}{F_{0}}\right)^{m}\right] .
$$

2.2.2. Statistical Damage Constitutive Model Considering Residual Strength. To reflect the postpeak behavior and residual strength, a compressed rock is divided into two

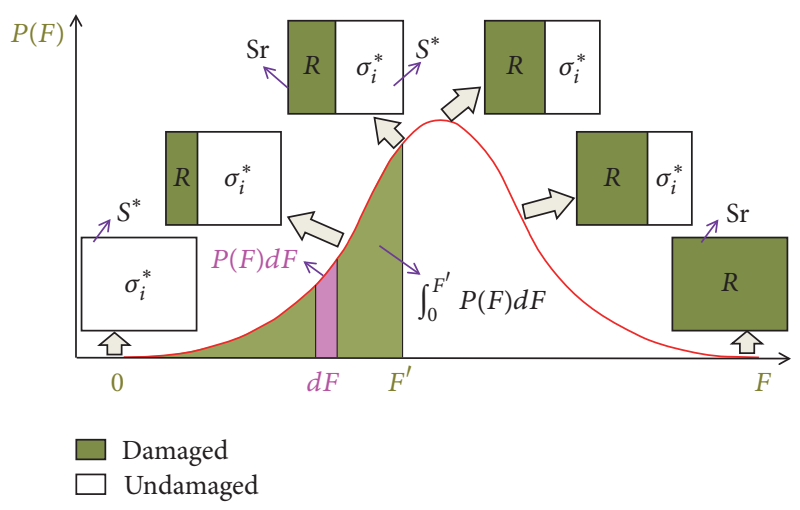

FIGURE 3: Weibull distribution and damage transition processes. These rectangles represent rocks with different degrees of damage. $S^{*}$ represents the undamaged area and the force of the undamaged area is determined by the net stress $\left(\sigma^{*}\right)$ of undamaged portion, while for damaged portion $(\mathrm{Sr})$, a residual strength $(R)$ is applied (modified from Zhao et al. [32]).

areas: damaged area $(\mathrm{Sr})$ and undamaged area $\left(S^{*}\right)$ (Figure 3). Strain-softening behavior can be performed by the degradation of the undamaged area. However, residual strength (i.e., residual stage) is difficult to illustrate without considering the net stress of the damaged area ( $\mathrm{Sr}$ ). In this new constitutive model, a net stress $(R)$ is applied on the damaged portion.

Assuming that the effective stress $\left(\sigma_{i}\right)$ on the total area of the specimen consists of the net stress $(R)$ on the damaged portion and net stress $\left(\sigma_{i}^{*}\right)$ on the undamaged portion, thus effective stress can be described as

$$
\sigma_{i}=\sigma_{i}^{*}(1-D)+R D .
$$

Net stress $(R)$ on the damaged portion (i.e., residual strength) can be determined by the Mohr-Coulomb criterion $[32,45]$. For a pure friction material $[3,46,47]$, peak strength increases linearly with the rise of residual strength $(R)$ and can be theoretical analyzed and expressed as

$$
R=a+b \sigma_{p}
$$

with

$$
\begin{gathered}
a=\frac{2 c_{r} \cos \varphi_{r}}{\left(1-\sin \varphi_{r}\right)}-\frac{2 c b \cos \varphi}{(1-\sin \varphi)}, \\
b=\frac{\left(1+\sin \varphi_{r}\right)(1-\sin \varphi)}{\left[(1+\sin \varphi)\left(1-\sin \varphi_{r}\right)\right]},
\end{gathered}
$$

where $\sigma_{p}$ is the peak strength under the PSBSS; $c$ and $\varphi$ are cohesive strength and internal frication angle in the elastic stage, respectively; $c_{r}$ and $\varphi_{r}$ are cohesive strength and internal frication angle in the residual strength stage, respectively. These parameters can be obtained by experimental test [45].

The undamaged portion is assumed to be elastic under the net stress of $\sigma_{i}^{*}$ and follows the generalized Hooke's law:

$$
\sigma_{i}^{*}=E^{*} \varepsilon_{i}^{*}+\mu^{*}\left(\sigma_{j}^{*}+\sigma_{k}^{*}\right),
$$


where $(i, j, k)=(1,2,3),(3,1,2)$, and $(2,1,3) ; E^{*}, \varepsilon_{i}^{*}$, and $\mu^{*}$ are the Young's modulus, strain, and Poisson's ratio, respectively. These microscopic parameters can be replaced by $E$, $\varepsilon_{i}$, and $\mu$, which are same parameters on the macroscale [19]. Thus, (8) can be modified as follows:

$$
\sigma_{i}^{*}=E \varepsilon_{i}+\mu\left(\sigma_{j}+\sigma_{k}\right) .
$$

Combining (1), (3), and (4) with (9), the modified statistical damage constitutive model for rocks under the PSBSS can be established and expressed as

$$
\begin{aligned}
\sigma_{1}= & \frac{E \varepsilon_{1}}{\left(1-\mu^{2}\right)}, \quad D=0 \\
\sigma_{1}= & \frac{E \varepsilon_{1}}{\left(1-\mu^{2}\right)} \\
& +\frac{\left(R-\mu R^{2}-E \varepsilon_{1}\right)}{\left(1-\mu^{2}\right)}\left\{1-\exp \left[-\left(\frac{F}{F_{0}}\right)^{m}\right]\right\}, \\
& \quad D>0 .
\end{aligned}
$$

\subsection{Determination of Parameters}

2.3.1. Modified Wiebols-Cook Criterion and PSBSS Peak Strength. Intermediate principle stress $\sigma_{2}$ plays an important role in determining the rock strength under the PSBSS. Criteria, such as Mohr-Coulomb, Hoek-Brown, and Tresca failure criterion, should not be considered when establishing new constitutive model because these criteria failed to take the intermediate principle stress into consideration. Colmenares and Zoback [48, 49] suggested that the modified WiebolsCook criterion and Modified Lade criterion achieved good fits to the true triaxial test data comparing with other five criteria, namely, Mohr-Coulomb, Hoek and Brown, DruckerPrager, and two empirical criteria. Because the modified Wiebols-Cook criterion estimated the failure strength more accurately for rocks which are highly dependent on the intermediate principle stress in this article [50], the modified
Wiebols-Cook criterion was adopted when establishing the statistical damage model in order to estimate the PSBSS peak strength.

As an extension of the Circumscribed Drucker-Prager criterion [51], the modified Wiebols-Cook criterion implies that a rock fails if

$$
J_{2}^{1 / 2}=A+B J_{1}+C J_{1}^{2}
$$

with

$$
\begin{aligned}
& J_{1}=\frac{\left(\sigma_{1}+\sigma_{2}+\sigma_{3}\right)}{3}, \\
& J_{2}=\frac{1}{6}\left[\left(\sigma_{1}-\sigma_{2}\right)^{2}+\left(\sigma_{1}-\sigma_{3}\right)^{2}+\left(\sigma_{2}-\sigma_{3}\right)^{2}\right],
\end{aligned}
$$

where $J_{1}$ and $J_{2}$ are the first and second deviatoric stress invariants, respectively. $A, B$, and $C$ are values which can be determined by mechanical and physical parameters of the material and can be expressed as

$$
\begin{aligned}
C & =\frac{\sqrt{27}}{2 C_{1}+(q-1) \sigma_{3}-\sigma_{c}}\left(\frac{C_{1}+(q-1) \sigma_{3}-\sigma_{c}}{2 C_{1}+(q-1) \sigma_{3}-\sigma_{c}}\right. \\
& \left.-\frac{q-1}{q+2}\right), \\
B & =\frac{\sqrt{3}(q-1)}{(q+2)}-\frac{\left[2 \sigma_{c}+(q+2) \sigma_{3}\right] C}{3}, \\
A & =\frac{\sigma_{c}}{\sqrt{3}}-B \frac{\sigma_{c}}{3}-C \frac{\sigma_{c}^{2}}{9},
\end{aligned}
$$

where $C_{1}=(1+0.6 \tan \varphi) \sigma_{c}$ and $q=\tan ^{2}(\pi / 4+\varphi / 2) ; \varphi$ and $\sigma_{c}$ are internal friction angle and uniaxial compression strength, respectively.

Thus, according to the elastic-constitutive relationship of rocks under the PSBSS (i.e., (1)) and (11) (16), the peak strength $\left(\sigma_{p}\right)$ under the PSBSS can be described as

$$
\sigma_{p}=\frac{\left[\sqrt{3} \sqrt{1+\mu^{2}-\mu}-B(1+\mu)\right]-\sqrt{\left[B(1+\mu)-\sqrt{3} \sqrt{1+\mu^{2}-\mu}\right]^{2}-4 A C(1+\mu)^{2}}}{2 C(1+\mu)^{2} / 3} .
$$

2.3.2. Drucker-Prager Criterion and Strength Level (F). The distribution parameter of mesoscopic element (strength level $(F)$ ) is correlated with damage variable $(D)$, as described in (3), and the strength level $(F)$ can be estimated by the failure criterion of rocks $[18,52]$. Tang and coworkers [53, 54] formulated the strength level in strain space. However, strength level is usually expressed by criteria in stress space instead of strain space. Two criteria, Mohr-Coulomb and
Drucker-Prager criteria $[20,52,55]$, are commonly adopted to determine the strength level in stress space.

The Drucker-Prager criterion for rocks under the PSBSS was employed and the value $F$ can be expressed as a function of its net stress and material parameters [20]:

$$
F=\alpha I_{1}^{*}+\sqrt{J_{2}^{*}}-K,
$$


with

$$
\begin{aligned}
I_{1}^{*} & =\sigma_{1}^{*}+\sigma_{2}^{*}+\sigma_{3}^{*}, \\
J_{2}^{*} & =\frac{1}{6}\left[\left(\sigma_{1}^{*}-\sigma_{2}^{*}\right)^{2}+\left(\sigma_{1}^{*}-\sigma_{3}^{*}\right)^{2}+\left(\sigma_{2}^{*}-\sigma_{3}^{*}\right)^{2}\right], \\
\alpha & =\frac{2 \sin \varphi}{[\sqrt{3}(3-\sin \varphi)]} \\
K & =\frac{6 c \cos \varphi}{[\sqrt{3}(3-\sin \varphi)]}
\end{aligned}
$$

where $\alpha$ and $K$ are material constants; $I_{1}^{*}$ and $J_{2}^{*}$ are the first stress invariant and second deviatoric stress invariant, respectively.

The strength level $(F)$ can be obtained by combining (4) and (18) (20):

$$
F=\frac{\left[\alpha(1+\mu)+\sqrt{3} / 3 \sqrt{1+\mu^{2}-\mu}\right]\left(\sigma_{1}-R D\right)}{(1-D)}-K .
$$

It should be noted that strength level $(F)$ determines the damage state of rock. When $F<0$, the rock is undamaged/ intact, while when $F \geq 0$, the rock is damaged.

\subsubsection{Extremum Method and Statistical Parameters ( $m$ and} $\left.F_{0}\right)$. The statistical parameters $m$ and $F_{0}$ determine the strain-softening behavior of rocks and can be calculated by the "extremum method" [56]. As shown in Figure 2, the derivative of stress should be equal to zero at the peak point of a stress-strain curve. Thus the boundary condition can be described as

$$
\frac{\partial \sigma_{1}}{\partial \varepsilon_{1}}\left(\sigma_{p}, \varepsilon_{p}\right)=0
$$

where $\sigma_{p}$ and $\varepsilon_{p}$ are peak stress and peak strain, respectively.

Differentiating (24), we can obtain

$$
m=\frac{E F_{p}}{\left[\left(R-2 \mu R-E \varepsilon_{p}\right) \ln \left(1-D_{p}\right) \partial F_{p} / \partial \varepsilon_{p}\right]},
$$

with

$$
\begin{gathered}
\frac{\partial F_{p}}{\partial \varepsilon_{p}}=\frac{\left[\alpha\left[\sigma_{p}(1+\mu)-3 R\right]+\sqrt{3} / 3 \sigma_{p} \sqrt{\mu^{2}-\mu+1}\right]}{\left(1-D_{p}\right)^{2}} \\
\cdot \frac{\partial D_{p}}{\partial \varepsilon_{p}}, \\
\frac{\partial D_{p}}{\partial \varepsilon_{p}}=\frac{\left[(2 \mu-1) R E+E\left(1-\mu^{2}\right) \sigma_{p}\right]}{\left(R-2 \mu R-E \varepsilon_{p}\right)^{2}},
\end{gathered}
$$

where $F_{p}$ and $D_{p}$ are the strength level and damage variable at the peak point, respectively. $F_{p}$ can be determined by (23); then $D_{p}$ can be identified by (10). Then statistical parameter $\left(F_{0}\right)$ can be rearranged by $(3)$ as

$$
F_{0}=\frac{F_{p}}{\left[-\ln \left(1-D_{p}\right)\right]^{1 / m}}
$$

Briefly, the stress-strain behavior of geomaterials can be illustrated by the following procedures:

(1) Input mechanical and physical parameters including Young's modulus $(E)$, Poisson's ratio $(\mu)$, internal friction angle $(\varphi)$, cohesive strength $(c)$, residual friction angle $\left(\varphi_{r}\right)$, and residual cohesive strength $\left(c_{r}\right)$.

(2) Determine the residual strength $(R)$ and peak strength $\left(\sigma_{p}\right)$ under the PSBSS by (5) and (17), respectively.

(3) Input the target range of strain into MATLAB for looping. Before looping, check the validity of the range.

(4) Loop for each strain and determine the value of the damage variable $(D)$. Then calculate the stress based on (10).

\section{Experimental Methodology}

3.1. Sample Description and Preparation. To validate the proposed constitutive model, brittle (coal) and ductile (synthetic materials) specimens were employed to conduct laboratory tests under the PSBSS. Coal specimens (Figures 4(a) and 4(b)), obtained from the \#3 coal seam at the 6303 longwall panel in the Baodian Coal Mine, China, were $70.7 \times 70.7 \times$ $70.7 \mathrm{~mm}^{3}$ in size. The average unit weight of coal specimen is $1360 \mathrm{~kg} / \mathrm{m}^{3}$.

Synthetic materials (Figure 4(c)) were $100 \times 100 \times$ $100 \mathrm{~mm}^{3}$ cube blocks and they were obtained by mixing the cemented sand and plaster. The weight percentages of the sand, cement, and plaster were $40 \%, 18 \%$, and $42 \%$, respectively. All synthetic specimens were prepared by using a specific mould (Figure 4(d)). The physical and mechanical parameters of the prepared coal and synthetic specimens are shown in Table 1.

3.2. Experimental Apparatus. An apparatus, modified from the surface instability detection apparatus $[30,57,58]$, was designed to achieve the PSBSS. A cube specimen can be placed between two rigid vertical sidewalls (Figure 5) and the adjustable wall, used to test specimens with different size, was bolted to prevent lateral deflection. Lube oil was adopted to minimize the friction at the interface. The compression experiments under the PSBSS were conducted on a rock servo-controlled system with a maximum loading capacity of $300 \mathrm{kN}$ and a maximum displacement resolution of $0.001 \mathrm{~mm}$. The strain control rate was $2.4 \times 10^{-4} / \mathrm{s}$.

\section{Validation Results and Discussion}

4.1. Stress-Strain Curves. The mechanical and statistical parameters of specimens can be determined (see Table 2) 


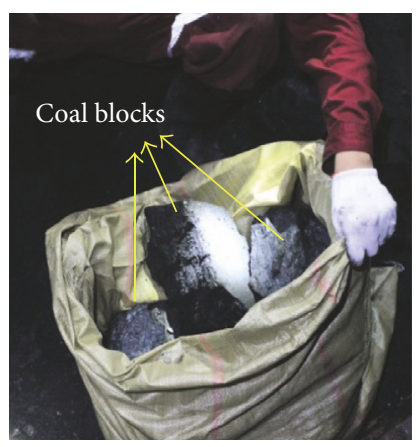

(a)

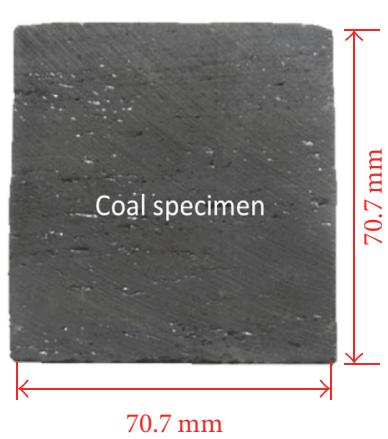

(b)

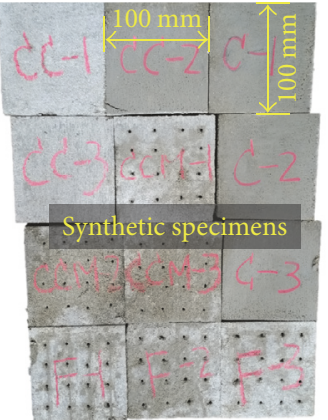

(c)

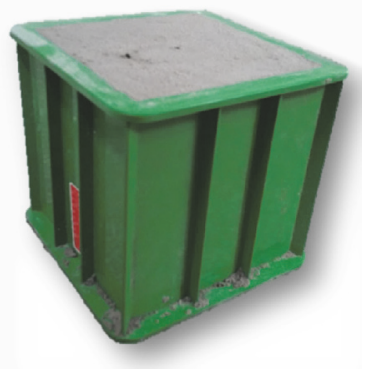

(d)

Figure 4: Coal blocks and specimens. (a) Coal blocks which are taken from the in situ working face; (b) coal specimens $(70.7 \times 70.7 \times$ $70.7 \mathrm{~mm}^{3}$ in size); (c) synthetic specimens $\left(100 \times 100 \times 100 \mathrm{~mm}^{3}\right.$ in size); (d) mould using for the preparation of specimens.

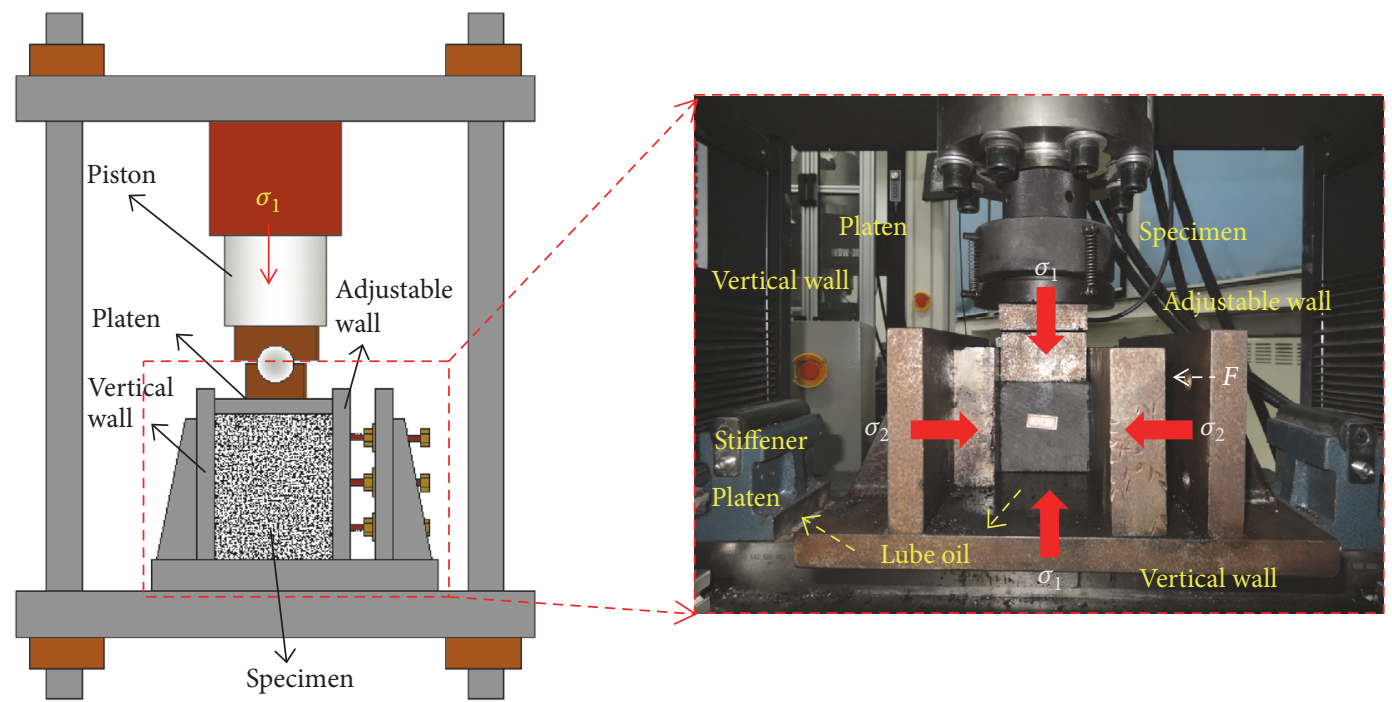

(a)

(b)

FIGURE 5: Plane-strain biaxial compression test system. (a) Schematic of test system; (b) paragraph of the experimental set-up.

TABLE 1: Mechanical and physical parameters of specimens.

\begin{tabular}{|c|c|c|c|c|}
\hline Parameters & Symbol/material & $\begin{array}{l}\text { Coal } \\
\text { value }\end{array}$ & $\begin{array}{c}\text { Synthetic material } \\
\text { value }\end{array}$ & Units \\
\hline Elastic modulus & $E$ & 1.070 & 0.115 & {$[\mathrm{GPa}]$} \\
\hline Uniaxial compression strength & $\sigma_{c}$ & 18.76 & 2.00 & {$[\mathrm{MPa}]$} \\
\hline Poisson's ratio & $\mu$ & 0.30 & 0.32 & N/A \\
\hline Cohesive strength & $c$ & 4.5 & 0.4 & {$[\mathrm{MPa}]$} \\
\hline Internal friction angle & $\varphi$ & 25 & 45 & {$\left[{ }^{\circ}\right]$} \\
\hline Residual cohesive strength & $c_{r}$ & $\sim 0.30$ & $\sim 0.15$ & {$[\mathrm{MPa}]$} \\
\hline Internal friction angle & $\varphi_{r}$ & $\sim 25$ & $\sim 45$ & {$\left[{ }^{\circ}\right]$} \\
\hline
\end{tabular}

TABLE 2: Parameters derived from the proposed model.

\begin{tabular}{|c|c|c|c|c|}
\hline Items & Symbols & Coal specimens (brittle) & Synthetic material (ductile) & Units \\
\hline PSBSS peak stress & $\sigma_{p}$ & 22.3 & 3.36 & {$[\mathrm{MPa}]$} \\
\hline Damage viable at peak stress & $D_{p}$ & $5.9 \%$ & $39.66 \%$ & {$[-]$} \\
\hline Statistical parameter & $m$ & 18.2 & 2.35 & {$[-]$} \\
\hline Statistical parameter & $F_{0}$ & 28.02 & 7.19 & {$[\mathrm{MPa}]$} \\
\hline Residual strength & $\sigma_{r}$ & 2.9 & 1.9 & {$[\mathrm{MPa}]$} \\
\hline
\end{tabular}




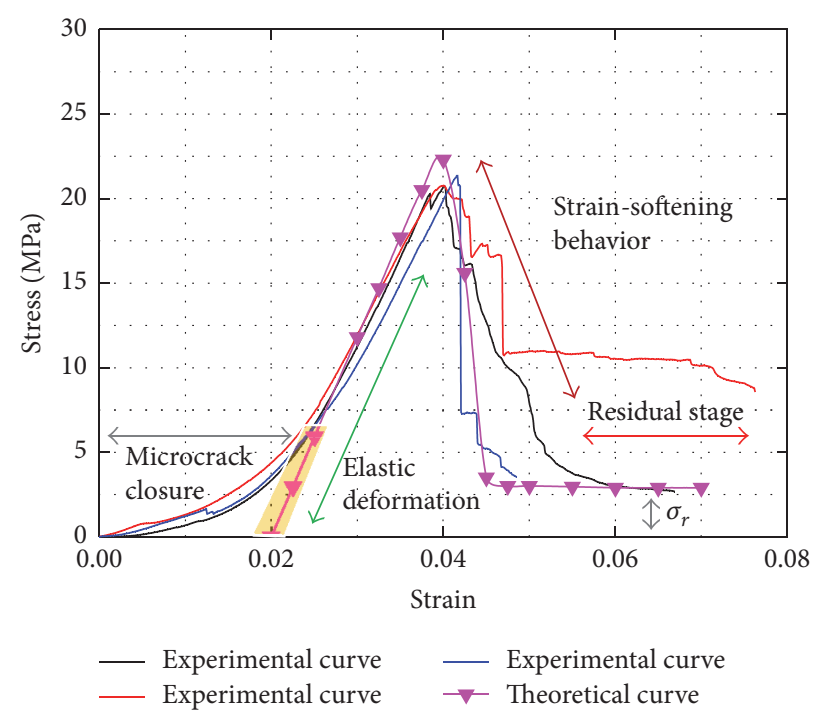

(a)

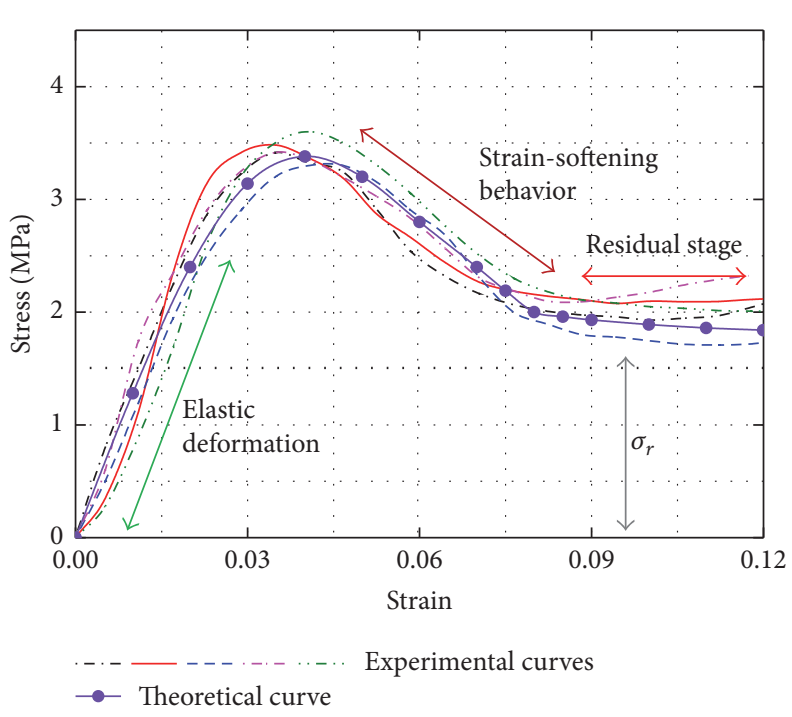

(b)

FIGURE 6: Strain-stress curves of experimental and theoretical data. (a) Stress-strain curves of coal under PSBSS; (b) stress-strain curves of synthetic material under PSBSS.

according to the parameters obtained from laboratory tests (Table 1). Stress-strain curves can be then plotted by employing the calculation procedure described in Section 2.3.3. Figure 6 illustrates the stress-strain curves derived from the experimental tests and the proposed statistical damage constitutive model. Figure 6(a) shows the stress-strain curves of coal specimens under the PSBSS, while Figure 6(b) presents the stress-strain curves of synthetic materials.

As shown in Figure 6(a), the stress-strain curves of coal specimens in the compression test under the PSBSS can be divided into four typical stages, namely, (1) original microcrack closure stage, (2) elastic deformation stage, (3) strain-softening stage, and (4) residual stage. In the first stage, stress-strain curve shows the downward concave because of the closure of some primary pores and voids. In the second stage, the loading force increases linearly with the axial stress. The peak strength can be obtained then and the strain-softening behavior follows by. With the generation and coalescence of cracks, an abrupt stress reduction occurs and finally the stress-strain curves reach the residual stage. Residual strengths are remarkable which may result from the confined pressure provided by the vertical walls, although the residual stages varied with the heterogeneity of coal specimens.

Figure 6(b) presents the stress-strain curves of synthetic materials obtained by the compression tests under the PSBSS. Similar to the stress-strain behavior of coal specimen, four typical stages can also be identified in the stress-strain curves of synthetic specimens. However, the original microcrack closure stages are unobvious, and strain-softening behavior and residual stage can be more easily identified compared to those of the coal specimen.

Theoretical curves of the coal specimen and synthetic materials are also presented in Figure 6. In general, the theoretical data has good agreement with the experimental observation and the typical stages (i.e., elastic deformation, strain-softening behavior, and residual stage) are well illustrated in theoretical curves. In the theoretical curves, the stress increases linearly with the strain prior to the peak strength. After the peak point, strain-softening behaviors occur. Finally, the theoretical curves reach the residual stage. Peak strengths calculated by the modified Wiebols-Cook criterion under the PSBSS and the residual strengths fit well with the experimental data. It should be noted that the original microcrack closure stages are difficult to illustrate in the new statistical damage constitutive model.

By comparing the stress-strain curves of coal specimens with that of synthetic specimens, we can easily find out that the strain-softening behaviors for two different materials are not the same. It also revealed that the damage in rocks has been initiated at the peak strength (i.e., peak damage variable $\left(D_{p}\right)$ is nonzero; see Table 2) $[19,33]$. These results in turn pose questions of what are the possible relations behind these parameters including statistical parameters $\left(m\right.$ and $\left.F_{0}\right)$ and physical parameters (peak strain and peak stress). Thus, the following parametric studies will examine the influence of peak strain on peak damage variation $\left(D_{p}\right)$ and statistical parameters ( $m$ and $F_{0}$ ) (see Section 4.2).

4.2. Effect of Peak Strain on Peak Damage Variable and Statistical Parameters. Parametric studies were conducted to estimate the effect of peak strain on damage variable and statistical parameters, and results for the synthetic material are shown in Figure 7. The results for the coal specimens are similar to the synthetic material. It is clear that peak strain has a strong influence on the peak damage variable $\left(D_{p}\right)$ and statistical parameters $\left(m\right.$ and $F_{0}$ ).

Figure 7(a) shows the peak damage variable increases logarithmically with the peak strain, while the statistical parameter $(m)$ experiences a decrease in an exponential manner. 


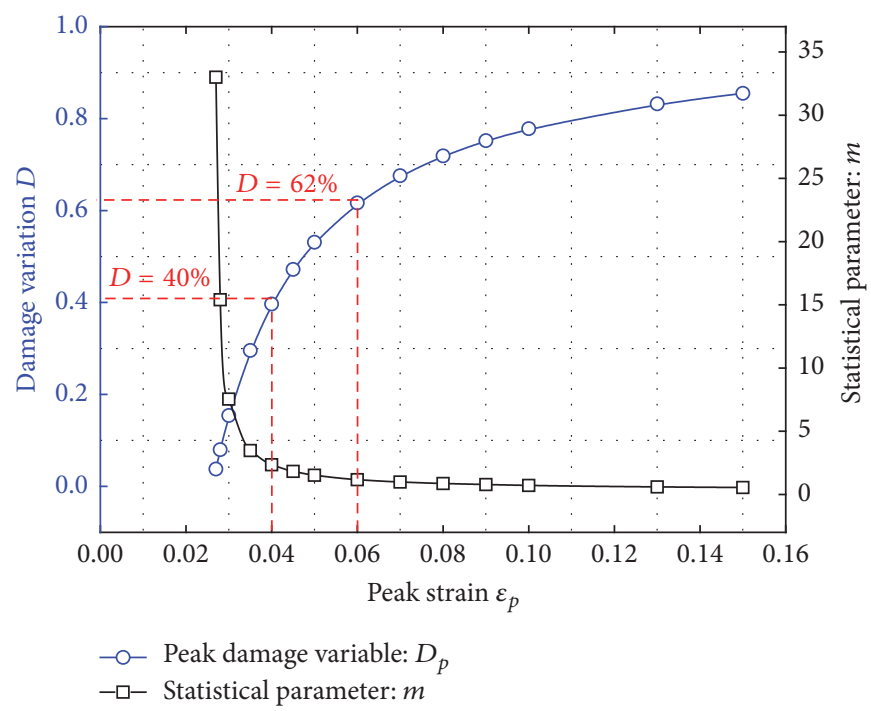

(a)

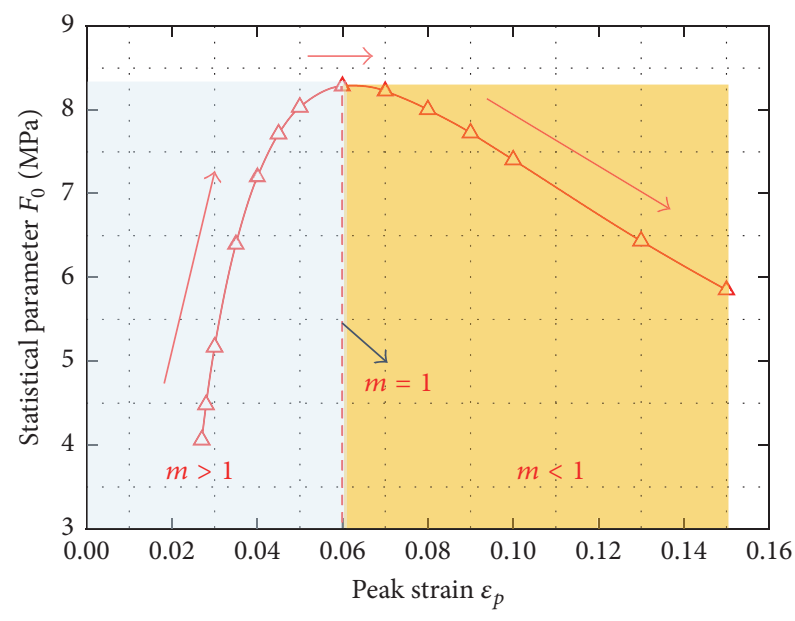

(b)

FIGURE 7: Relationships between physical parameters and statistical parameters. (a) Effects of peak strain on peak damage variable and parameter $(m)$; (b) effects of peak strain on parameter $F_{0}$.

Thus we can conclude that a higher peak strain implies a higher damage variable $\left(D_{p}\right)$ and a lower statistical parameter $m$. According to the damage theory, the statistical parameter ( $m$ ) determines the softening behavior of the constitutive model, and a larger $m$ implies a higher uniformity and a higher brittleness [52]. However, statistical parameter $\left(F_{0}\right)$ can be divided into two stages (Figure 7(b)). Prior to the peak strain of 0.06 , this parameter experiences an increase, while, with a peak strain larger than 0.06 , the statistical parameter $F_{0}$ decreases. Thus, peak strain can affect these mentioned parameters in different ways and should be carefully predetermined or tested. Also, as a compromise parameter, the peak strain can be adjusted in a small scale to fit the postpeak curve.

\section{Conclusions}

By employing the basic theory of damage mechanics, we established a statistical damage constitutive model for rocks under the PSBSS. The modified model was validated by the experimental results for brittle and ductile materials. On the basis of the analyses and calculation of this model, the following conclusion can be drawn:

(1) An effective theoretical model to simulate the stressstrain curves of brittle and ductile rocks under the PSBSS is presented. In this new model, the modified Wiebols-Cook criterion, Druck-Prager criterion, and extremum method were employed to estimate the peak strength under the PSBSS, strength level, and statistical parameters, respectively.

(2) Comparisons between the experimental and theoretical results were made and the results show that the modified constitutive model provided a good prediction of the stress-strain curves of rocks under the PSBSS tests. In particular, the calculated peak strength, strain-softening behavior, and residual strength fit well with the experimental data.

(3) Strain-softening behavior in this model is determined by statistical parameters $m$ and $F_{0}$. Peak strain which should be carefully predetermined or tested can affect parameters $m$ and $F_{0}$ in different manners.

\section{Conflicts of Interest}

The authors declare no conflicts of interest.

\section{Acknowledgments}

This work was supported by the National Basic Research Program of China [2014CB046300] and by the Priority Academic Program Development of Jiangsu Higher Education Institutions (PAPD).

\section{References}

[1] E. Hoek and E. T. Brown, "Practical estimates of rock mass strength," International Journal of Rock Mechanics and Mining Sciences, vol. 34, no. 8, pp. 1165-1186, 1997.

[2] H. Kupfer, H. K. Hilsdorf, and H. Rusch, "Behavior of concrete under biaxial stresses," Journal of American Concrete Institute, vol. 66, no. 8, pp. 656-666, 1969.

[3] F. Rummel and C. Fairhurst, "Determination of the postfailure behavior of brittle rock using a servo-controlled testing machine," Rock Mechanics and Rock Engineering, vol. 2, no. 4, pp. 189-204, 1970.

[4] R. Hooke and T. A. Jeeves, "Direct search solution of numerical and statistical problems," Journal of Association for Computing Machinery, vol. 8, no. 2, pp. 212-229, 1961. 
[5] N. G. W. Cook, “The failure of rock," International Journal of Rock Mechanics and Mining Sciences \& Geomechanics Abstracts, vol. 2, no. 4, pp. 389-403, 1965.

[6] K. Mogi, "Effect of the intermediate principal stress on rock failure," Journal of Geophysical Research, vol. 72, no. 20, pp. 51175131, 1967

[7] G. A. Wiebols and N. G. W. Cook, "An energy criterion for the strength of rock in polyaxial compression," International Journal of Rock Mechanics and Mining Sciences \& Geomechanics Abstracts, vol. 5, no. 6, pp. 529-549, 1968.

[8] L. S. Costin, "A microcrack model for the deformation and failure of brittle rock," Journal of Geophysical Research: Solid Earth, vol. 88, no. B11, pp. 9485-9492, 1983.

[9] E. Hoek, D. Wood, and S. Shah, "Modified Hoek-Brown failure criterion for jointed rock masses," International Journal of Rock Mechanics and Mining Sciences \& Geomechanics Abstracts, vol. 30, no. 4, p. A215, 1993.

[10] L. Yudhbir, W. Lemanza, and F. Prinzl, "An empirical failure criterion for rock masses," in Proceedings of the Fifth International Congress on Rock Mechanics, Melbourne, Australia, 1983.

[11] M. S. Paterson and T. F. Wong, Experimental Rock Deformation The Brittle Field, 2005.

[12] M. You, "True-triaxial strength criteria for rock," International Journal of Rock Mechanics and Mining Sciences, vol. 46, no. 1, pp. 115-127, 2009.

[13] J. F. Labuz and A. Zang, "Mohr-Coulomb failure criterion," Rock Mechanics and Rock Engineering, vol. 45, no. 6, pp. 975-979, 2012.

[14] W. Weibull, "A Statistical Distribution Function of Wide Applicability," Journal of applied mechanics, pp. 293-297, 1951.

[15] J. Lubliner, J. Oliver, S. Oller, and E. Oñate, "A plastic-damage model for concrete," International Journal of Solids and Structures, vol. 25, no. 3, pp. 299-326, 1989.

[16] D. Krajcinovic and M. A. G. Silva, "Statistical aspects of the continuous damage theory," International Journal of Solids and Structures, vol. 18, no. 7, pp. 551-562, 1982.

[17] J. Lemaitre, "A continuous damage mechanics model for ductile fracture," Journal of Engineering Materials and Technology, vol. 107, no. 1, pp. 83-89, 1985.

[18] C. A. Tang, "Numerical simulation of progressive rock failure and associated seismicity," International Journal Of Rock Mechanics And Mining Sciences \& Geomechanics Abstracts, vol. 34, no. 2, pp. 249-261, 1997.

[19] X. Li, W.-G. Cao, and Y.-H. Su, "A statistical damage constitutive model for softening behavior of rocks," Engineering Geology, vol. 143-144, pp. 1-17, 2012.

[20] J. Deng and D. Gu, "On a statistical damage constitutive model for rock materials," Computers \& Geosciences, vol. 37, no. 2, pp. 122-128, 2011.

[21] C. A. Tang, H. Liu, P. K. K. Lee, Y. Tsui, and L. G. Tham, "Numerical studies of the influence of microstructure on rock failure in uniaxial compression-part I: effect of heterogeneity," International Journal of Rock Mechanics and Mining Sciences, vol. 37, no. 4, pp. 555-569, 2000.

[22] W. C. Zhu, J. Liu, C. A. Tang, X. D. Zhao, and B. H. Brady, "Simulation of progressive fracturing processes around underground excavations under biaxial compression," Tunnelling and Underground Space Technology, vol. 20, no. 3, pp. 231-247, 2005.

[23] C. A. Tang, P. Lin, R. H. C. Wong, and K. T. Chau, "Analysis of crack coalescence in rock-like materials containing three flaws-Part II: Numerical approach," International Journal of
Rock Mechanics and Mining Sciences, vol. 38, no. 7, pp. 925-939, 2001.

[24] K. L. Soserman and J. P. Giroud, "Relationships between Uniaxial and Biaxial Stresses and Strains in Geosynthics," Geosynthetics International, vol. 2, no. 2, pp. 495-504, 1995.

[25] M. Mokni and J. Desrues, "Strain localization measurements in undrained plane-strain biaxial tests on Hostun Rf sand," Mechanics of Cohesive-frictional Materials, vol. 4, no. 4, pp. 419441, 1999.

[26] G. V. Basheev, P. A. Martynyuk, and E. N. Sher, "Statistical modeling of rock failure under biaxial compression. Part I: Shear crack interaction," Journal of Mining Science, vol. 39, no. 5, pp. 467-474, 2003.

[27] H. Wang and Y. Song, "Behavior of dam concrete under biaxial compression-tension and triaxial compression-compressiontension stresses," Frontiers of Architecture and Civil Engineering in China, vol. 2, no. 4, pp. 323-328, 2008.

[28] P. H. S. W. Kulatilake, J. Park, and B. Malama, "A new rock mass failure criterion for biaxial loading conditions," Geotechnical and Geological Engineering, vol. 24, no. 4, pp. 871-888, 2006.

[29] R. Makhnenko and J. Labuz, "Plane Strain Testing with Passive Restraint," Rock Mechanics and Rock Engineering, vol. 47, no. 6, pp. 2021-2029, 2013.

[30] E. Papamichos, J. F. Labuz, and I. Vardoulakis, "A surface instability detection apparatus," Rock Mechanics and Rock Engineering, vol. 27, no. 1, pp. 37-56, 1994.

[31] Z. Tao, Theory and Practice of Rock Mechanics, Wuhan University: Wuhan, 2013.

[32] H. Zhao, C. Shi, M. Asce, M. Zhao, and X. Li, "Statistical damage constitutive model for rocks considering residual strength," International Journal of Geomechanics, vol. 16, no. 4, pp. 1-9, 2017.

[33] S.-H. Chang and C.-I. Lee, "Estimation of cracking and damage mechanisms in rock under triaxial compression by moment tensor analysis of acoustic emission," International Journal of Rock Mechanics and Mining Sciences, vol. 41, no. 7, pp. 10691086, 2004.

[34] R. L. Kranz, "Microcracks in rocks: A review," Tectonophysics, vol. 100, no. 1-3, pp. 449-480, 1983.

[35] H. Horii and S. Nemat-Nasser, "Compression-induced microcrack growth in brittle solids: Axial splitting and shear failure," Journal of Geophysical Research, vol. 90, no. B4, pp. 3105-3125, 1985.

[36] H. Haeri, A. Khaloo, and M. F. Marji, "Experimental and numerical simulation of the microcrack coalescence mechanism in rock-like materials," Strength of Materials, vol. 47, no. 5, pp. 740-754, 2015.

[37] O. Alm, L.-L. Jaktlund, and K. Shaoquan, "The influence of microcrack density on the elastic and fracture mechanical properties of Stripa granite," Physics of the Earth and Planetary Interiors, vol. 40, no. 3, pp. 161-179, 1985.

[38] D. Su, M. H. Santare, and G. A. Gazonas, "The effect of crack face contact on the anisotropic effective moduli of microcrack damaged media," Engineering Fracture Mechanics, vol. 74, no. 9, pp. 1436-1455, 2007.

[39] M. Oda, T. Katsube, and T. Takemura, "Microcrack evolution and brittle failure of Inada granite in triaxial compression tests at $140 \mathrm{MPa}$, Journal of Geophysical Research: Solid Earth, vol. 107, no. B10, pp. ECV 9-1-ECV 9-17, 2002.

[40] A. P. Jivkov, "Structure of micro-crack population and damage evolution in quasi-brittle media," Theoretical and Applied Fracture Mechanics, vol. 70, pp. 1-9, 2014. 
[41] W. Xu and L. Wei, "Study on statistical damage constitutive mode of rock," Chinese Journal of Rock Mechanics and Engineering, vol. 21, no. 6, pp. 787-791, 2002.

[42] Z.-L. Wang, Y.-C. Li, and J. G. Wang, "A damage-softening statistical constitutive model considering rock residual strength," Computers \& Geosciences, vol. 33, no. 1, pp. 1-9, 2007.

[43] B. H. G. Brady and J. W. Bray, "Boundary element method for determining stresses and displacements around long openings in a triaxial stress field," International Journal of Rock Mechanics and Mining Sciences \& Geomechanics Abstracts, vol. 15, no. 5, pp. A103-A103, 1978.

[44] J. B. Keats, F. P. Lawrence, and F. K. Wang, "Weibull maximum likelihood parameter estimates with censored data," Journal of Quality Technology, vol. 29, no. 1, pp. 105-110, 1997.

[45] M. Cai, P. K. Kaiser, Y. Tasaka, and M. Minami, “Determination of residual strength parameters of jointed rock masses using the GSI system," International Journal of Rock Mechanics and Mining Sciences, vol. 44, no. 2, pp. 247-265, 2007.

[46] K. Hashiba, S. Okubo, and K. Fukui, "A new testing method for investigating the loading rate dependency of peak and residual rock strength," International Journal of Rock Mechanics and Mining Sciences, vol. 43, no. 6, pp. 894-904, 2006.

[47] W. G. Pariseau, "Fitting failure criteria to laboratory strength tests," International Journal of Rock Mechanics and Mining Sciences, vol. 44, no. 4, pp. 637-646, 2007.

[48] L. B. Colmenares and M. D. Zoback, "A statistical evaluation of intact rock failure criteria constrained by polyaxial test data for five different rocks," International Journal of Rock Mechanics and Mining Sciences, vol. 39, no. 6, pp. 695-729, 2002.

[49] L. B. Colmenares and M. D. Zoback, "Statistical evaluation of six rock failure criteria constrained by polyaxial test data," Rock Mechantcs tn Nattonal Interes. Elsworth, Ttnucct Heasley, pp. 1251-1258, 2001.

[50] H. Rafiai, "New empirical polyaxial criterion for rock strength," International Journal of Rock Mechanics \& Mining Sciences, vol. 48, no. 6, pp. 922-931, 2011.

[51] S. Zhou, "A program to model the initial shape and extent of borehole breakout," Computers and Geosciences, vol. 20, no. 7-8, pp. 1143-1160, 1994.

[52] W. Cao, Z. Fang, and X. Tang, "A study of statistical constitutive model for soft and damage rocks," Chinese Journal of Rock Mechanics and Engineering, vol. 17, no. 6, pp. 628-633, 1988.

[53] C. Tang, J. A. Hudson, and X. H. Xu, Rock Failure Instability and Related Aspects of Earthquake Mechanisms, China Coal Industry Publishing House, Beijing, China, 1993.

[54] W. C. Zhu and C. A. Tang, "Micromechanical model for simulating the fracture process of rock," Rock Mechanics and Rock Engineering, vol. 37, no. 1, pp. 25-56, 2004.

[55] D. C. Drucker and W. Prager, "Soil mechanics and plastic analysis or limit design," Quarterly of Applied Mathematics, vol. 10, no. 2, pp. 157-165, 1952.

[56] B. Friedman, Principles and techniques of applied mathematics, John Wiley \& Sons,Inc., New York, USA, 1956.

[57] N. F. Ince, C.-S. Kao, M. Kaveh, A. Tewfik, and J. F. Labuz, "A machine learning approach for locating acoustic emission," Eurasip Journal on Advances in Signal Processing, vol. 2010, no. 1, Article ID 895486, 2010.

[58] J. Labuz, S. Dai, and E. Papamichos, "Plane-strain compression of rock-like materials," International Journal of Rock Mechanics and Mining Sciences \& Geomechanics Abstracts, vol. 33, no. 6, pp. 573-584, 1996. 


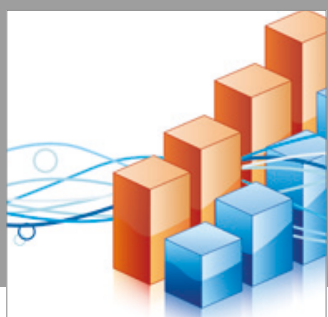

Advances in

Operations Research

vatersals

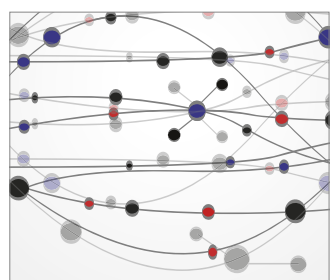

\section{The Scientific} World Journal
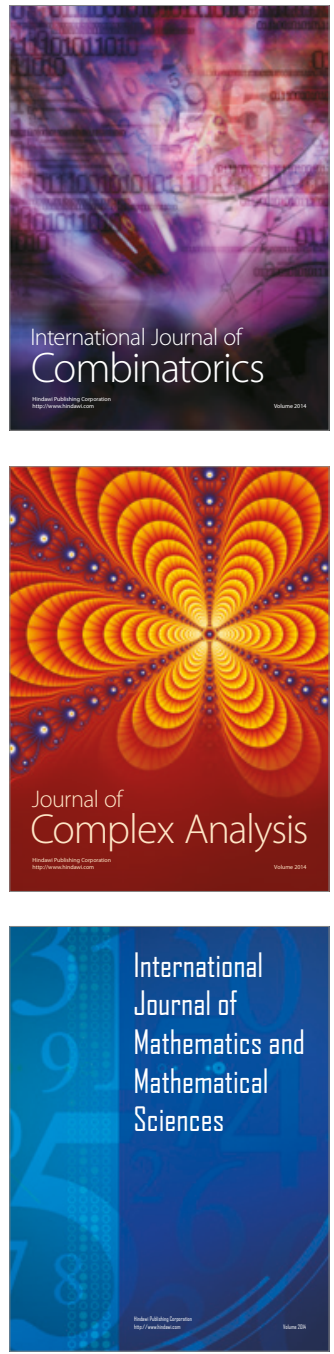
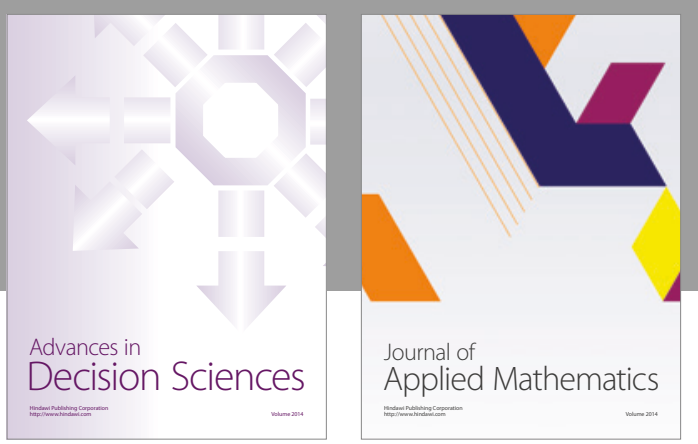

Algebra

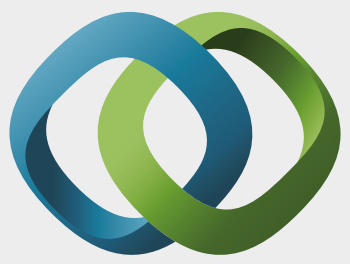

\section{Hindawi}

Submit your manuscripts at

https://www.hindawi.com
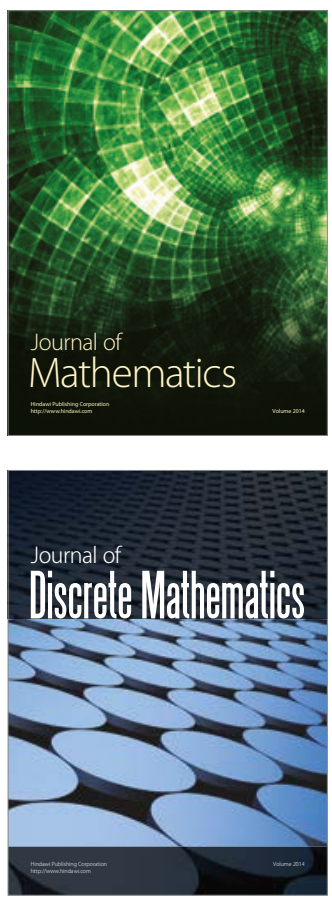

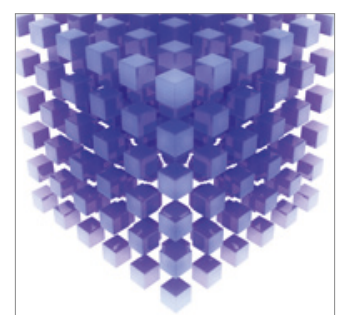

Mathematical Problems in Engineering
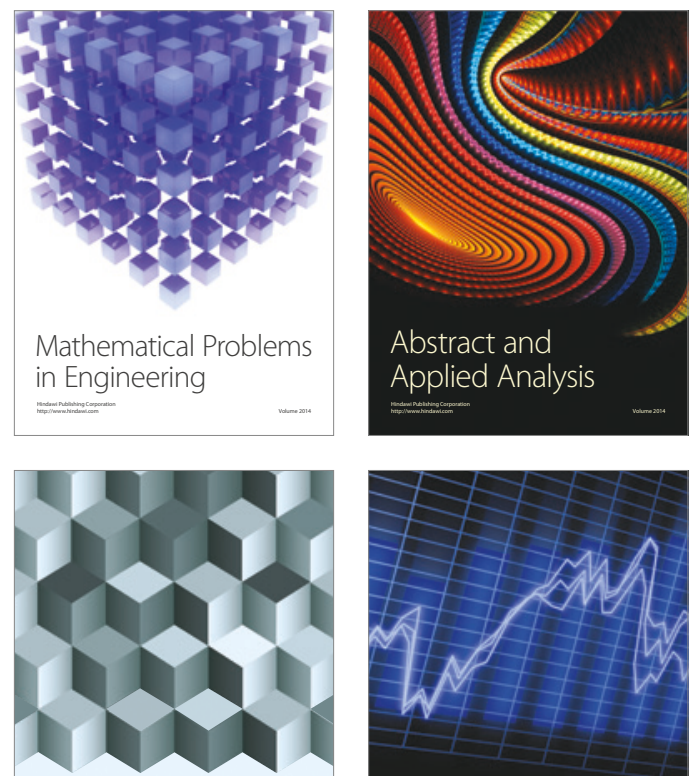

Journal of

Function Spaces

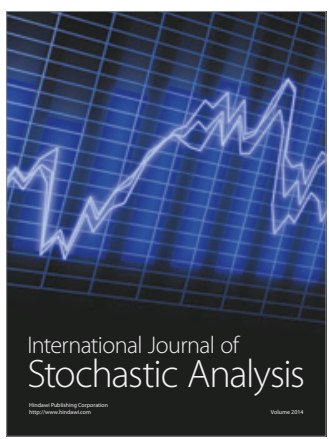

Probability and Statistics
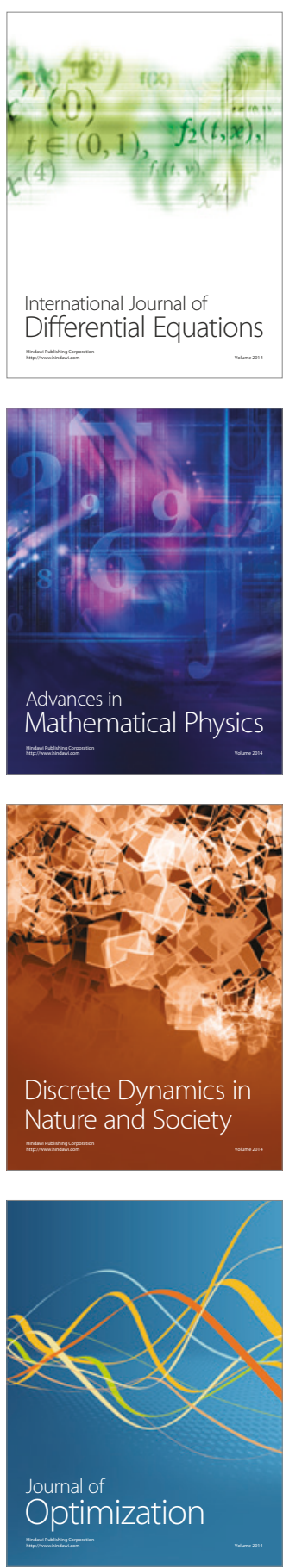